Territorios 31 / Bogotá, 2014, pp. 57-83

ISSN: 0123-8418

ISSNe: 2215-7484

Acción colectiva en las ciudades latinoamericanas

\title{
Acciones colectivas contenciosas, proceso político y seguridad urbana. Construyendo geografías de la esperanza
}

Contentious Collective Action, Political Process and Urban Security. Building Geographies Hope

Ações coletivas contenciosas, processo politico e segurança urbana. Construindo geografias da esperança

Luis Berneth Peña*

Recibido: 29 de junio de 2014

Aprobado: 31 de septiembre de 2014

Doi: dx.doi.org/10.12804/territ31.2014.03

Para citar este artículo:

Peña, L. (2014). Acciones colectivas contenciosas, proceso político y seguridad urbana. Construyendo geografías de la esperanza. Territorios, (31), 57-83. Doi: dx.doi.org/10.12804/territ31.2014.03

* Geógrafo de la Universidad Nacional de Colombia; magister en Planeación Territorial, Geografía y Sociedad de la Universidad Rennes 2 (Francia); doctorando en Geografía Social, de la Universidad Rennes 2. Correo electrónico: lberneth@gmail.com 
Palabras clave

Acción colectiva contenciosa, politica popular, organizaciones sociales, ciudad y movilización social, seguridad urbana, geografía politica urbana, Ciudad Bolivar, San Cristóbal, Bogotá.

Keywords

Contentious collective action, popular politics, social organizations, city and social mobilization, urban security, urban political geography, Ciudad

Bolivar, San Cristóbal, Bogotá.

Palavras-chave Ação coletiva contenciosa, politica popular, organizações sociais, cidade e mobilização social, segurança urbana, geografia politica urbana, Ciudad Bolivar, San Cristóbal, Bogotá.

\section{territarias 31}

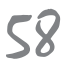

\section{RESUMEN}

Este artículo describe algunos repertorios y redes de acciones colectivas contenciosas (acciones populares que buscan construir o profundizar derechos) desplegadas por algunas organizaciones sociales en Bogotá que promueven formas no autoritarias de seguridad urbana. Basado en una perspectiva espacial de la acción colectiva, se enfatiza en el lugar de la política popular en los procesos políticos y la política de lugar en la que se construyen nuevas formas de solidaridad fundamentadas en arraigos comunitarios. En la primera sección, se expone el concepto de acción colectiva contenciosa. La segunda describe la estructura espacial de la acción colectiva de las organizaciones sociales en dos escalas: a) la escala de una localidad (Ciudad Bolívar) y b) la escala de un proyecto donde convergen varias organizaciones en el barrio Los Libertadores en la localidad de San Cristóbal. En la tercera, se presentan algunos ejemplos del repertorio de confrontación de las organizaciones. En la última parte, se discuten los resultados encontrados.

\section{ABSTRACT}

This article describes some repertoires and networks of contentious collective actions (popular actions pursuing to build and deepen rights) unfolded for social organizations in Bogotá aiming to promote non-authoritarian forms of urban security. Based on a spatial perspective of collective action, this article emphasizes the place of popular politics in the political process, and the politics of place in which new forms of solidarity are built based on community ties. In the first section is exposed the concept of contentious collective action. The second one present two scales of the collective action: a) the scale of a locality (the district of Ciudad Bolívar in Bogotá) and; b) the scale of a project where several organizations converge in the neighborhood of Los Libertadores in San Cristóbal. In the third section, are presented some actions of the organization's repertoire of confrontation. In the final the results part are discussed.

\section{RESUMO}

Este artigo descreve alguns repertórios e redes de ações coletivas contenciosas (ações populares que buscam construir ou aprofundar direitos) realizadas por algumas organizações sociais em Bogotá que promovem formas não autoritárias de segurança urbana. Baseado em uma perspectiva espacial da ação coletiva, enfatiza-se no lugar da política popular nos processos políticos, e a política de lugar na que se constroem novas formas de solidariedade fundamentadas em enraizamentos comunitários. Na primeira seção, expõe-se o conceito de ação coletiva contenciosa. A segunda descreve a estrutura espacial da ação coletiva das organizações sociais em duas escalas: a) a escala de uma localidade (Ciudad Bolívar) e b) a escala de um projeto onde convergem várias organizações no bairro Los Libertadores na localidade de San Cristóbal. Na terceira, apresentam-se alguns exemplos do repertório de confrontação das organizações. Na última parte, discutem-se os resultados encontrados. 


\section{Introducción}

Este artículo recoge varias experiencias de investigación propias con organizaciones sociales. Se busca describir algunos repertorios y redes de acciones que despliegan estas en la promoción de formas no autoritarias de seguridad urbana en Bogotá. Se centra en las acciones colectivas contenciosas, es decir, en las acciones populares efectuadas por organizaciones y redes de organizaciones que buscan construir y profundizar derechos. El eje del análisis es la espacialización de la acción colectiva contenciosa, el cual tiene un doble propósito: a) analizar el despliegue espacial de la acción colectiva en el marco de la preocupación por los procesos políticos populares, para lo cual nos servimos de las redes de acciones y el repertorio de confrontación; y b) el proceso de construcción de lugar, como territorialización de las solidaridades y, en ese sentido, como eje de las disputas territoriales entre actores (las organizaciones sociales y los agentes generadores de inseguridad) con motivaciones e intencionalidades contrapuestas. Se busca con este enfoque espacial destacar tanto la innovación política que ejercen las organizaciones sociales como plantear inquietudes sobre la manera en la que se ha analizado la acción colectiva.

Este artículo no trata de la community policing (tema muy extendido en las ciencias sociales) en la que el interés fundamental es ver cómo la comunidad se organiza para perseguir criminales y delincuentes, o define rondas de vigilancia (Consortium, 1994; Friedmann, 1992; Goldstein, 1987; Greene
\& Mastrofski, 1988; Moore, 1992; Peak \& Glensor, 1999). Se trata más bien de un tipo de acción colectiva contenciosa destinada a transformar formas de apropiación espacial y la sociabilidad urbana. Se trata de discutir el lugar de la política popular en los procesos políticos y las políticas de lugar en el que se construyen solidaridades alternativas sobre la base de arraigos territoriales.

El artículo está organizado de la siguiente manera: en la primera sección, se expone el concepto de acción colectiva contenciosa. La segunda describe la estructura espacial de la acción colectiva de las organizaciones sociales en dos escalas: a) la escala de una localidad (Ciudad Bolívar) y b) la escala de un proyecto donde convergen varias organizaciones en el barrio Los Libertadores en la localidad de San Cristóbal. En la tercera, se presentan algunos ejemplos del repertorio de confrontación de las organizaciones. En la última parte, se discuten los resultados.

\section{El espacio social en las teorías de la acción colectiva contenciosa}

Las ciencias sociales han venido especificando la investigación sobre la acción colectiva contenciosa y han pasado de las explicaciones sobre el comportamiento colectivo a la teorización sobre el proceso político popular, atravesando, por supuesto, las teorías de los movimientos sociales y las teorías espaciales o territoriales de la acción colectiva. ${ }^{1}$ En ese abanico de perspectivas rivales y complementarias, se encuentran posturas como: ${ }^{2}$
Para un estado del arte de la acción colectiva contenciosa, ver McAdam, Tarrow y Tilly, 2003; Melucci, 1988, 1994, 1999; Tarrow, 2011; Tilly, 2003, 2005; Tilly y Tarrow, 2006.

${ }^{2}$ Aqui una lista de otrosenfoques: las estructuralistas (en la que la acción colectiva se ajusta a las divisiones de la organización social a las que las teorias disponibles sobre la estructura y cambio asignan capacidades $e$ intereses distintivos), las racionalistas (que interpretan la participación en una acción contenciosa como un acto racional basado en la evaluación de beneficios, los recursos y las limitaciones situacionales), las fenomenológicas (que preguntan por la formación del estado de conciencia que permite a una persona comprometerse en una política de oposición); las culturalistas (que atribuyen poder causal para la movilización a las normas, los valores, las creencias y los simbolos que laspersonasexperimentany absorben) (Tilly, McAdam y Tarrow, 2001, p. 21).

\section{territarias 31}

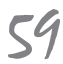


1. La teoría de movilización de recursos, para la que la acción colectiva contenciosa no resulta de la agregación de individuos atomizados, sino de las complejas redes de pertenencia que se construyen o destruyen sobre la evaluación de las posibilidades y restricciones que las personas que trabajan por un objetivo común encuentran dentro de sus marcos de vida. Esta resalta la importancia de los 'recursos discrecionales' disponibles y de la 'estructura de oportunidades' que hace posible la acción, y revelan lo inapropiado de la ecuación descontento (frustración) = movilización (agregación), subrayando la importancia de ciertas condiciones del ambiente político para entender la acción colectiva (McAdam, McCarthy \& Zald, 1988, 1996; McCarthy \& Zald, 1977).

2. La teoría del proceso político, que crítica la paralización de la teoría de la movilización de recursos y hace énfasis en la dinámica de contención introduciendo una teoría de la (acción) política popular consistente, básicamente, en no restarle importancia a la contingencia, la emocionalidad, la plasticidad y al entrecruce de fuerzas e influencia en la conformación de la política popular. La teoría del proceso político critica la manera como es entendida la identidad, los 'recursos discrecionales', la 'estructura de oportunidades', las 'estructuras de movilización', los 'marcos de acción colectiva' y 'el repertorio de acciones contenciosas', y sostiene que no se refieren a realidades fijas y solo 'objetivas', sino a la capacidad del actor para percibir, evaluar y determinar las posibilidades y límites de su ambiente. Los teóricos del proceso político se interesan por ver cómo cambian los rasgos que caracterizan la acción colectiva y, si bien se reconoce que la política popular tiene una alta complejidad organizacional, no se puede solidificar y enmarcar toda la acción colectiva en un modelo estático y 'racional' (entiéndase, un involucramiento calculado en pos de la disputa de recursos) de acción política (Tilly, McAdam \& Tarrow, 2001).

3. Las perspectivas territoriales de la acción colectiva llaman la atención sobre el lugar de la política y la política del lugar donde se entiende que los conflictos, la identidad colectiva, las redes, la oportunidades y constreñimientos están enraizados territorialmente (Escobar \& Restrepo, 2010; Oslender, 2007). Estos entienden la acción colectiva como un proceso político atravesado por la disputa entre prácticas, representaciones y proyectos de espacialidad contrapuestos. Es por eso por lo que hay que partir de una perspectiva espacial de la conflictividad que se sustenta en la problematización de los dominios de relaciones que describen la espacialidad y la cual hemos llamamos la matriz espacial (Peña, 2008). Dicha matriz espacial está compuesta por tres grandes dominios:

\section{territarias 31}

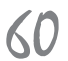


a) En el dominio de las relaciones sociedad-naturaleza o sociedad-medio ambiente, en el que están los conflictos relativos a las contradicciones entre ritmos de la naturaleza y los ritmos de la acumulación capitalista y las contradicciones derivadas de la apropiación, uso y significados diversos de los recursos y la naturaleza.

b) El dominio de las relaciones entre la sociedad y el espacio, en el que se encuentran las contradicciones producto del choque entre la lógica territorial capitalista de producción del espacio con las prácticas y las representaciones espaciales de las personas y comunidades. La lógica territorial del capitalismo se expresa en variadas estrategias (la reducción de costos de producción, la innovación técnica y organizacional, la disminución de la fricción espacial vía las desregulaciones a favor del capital, la inversión en infraestructuras y la acumulación por despojo) para hacer más expedita, acelerada y cada vez más voluminosa la acumulación de ganancias. El despliegue de dichas estrategias causa pugnas sociales con quienes ven afectadas sus formas de vida, su libertad o sus intereses (Harvey, 2007, 2004).

c) En el dominio de las relaciones de los sujetos con los lugares en donde se encuentran conflictos derivados de: (i) la confrontación entre visiones, prácticas y representaciones de las personas y comunidades con los proyectos de actores extra locales; (ii) el antagonismo entre apropiaciones tradicionales o no modernas con visiones utilitaristas y mercantilistas del espacio; (iii) cortes bruscos en el arraigamiento de las personas a los lugares; (iv) imposibilidad de relacionamiento distensionado con las demás personas en diversos escenarios; (v) experiencias inauténticas de no lugar; (vi) la búsqueda de nuevas configuraciones y apropiaciones del espacio-tiempo cotidiano frente a las establecidas de manera hegemónica (Peña, L. 2008).

Lo pertinente de los diversos enfoques territoriales es que entienden la acción colectiva como un proceso en el que existen unas conflictualidades espaciales y que se expresa, en consecuencia, como disputas derivadas de la territorialización de proyectos económicos, sociales y culturales antagónicos (Mançano, 2009, 2012). Estos enfoques territoriales de la acción colectiva hacen énfasis en la politización del sentido de lugar y destacan que la búsqueda de territorialidades alternativas se expresa en reivindicaciones de apropiación diferentes del espacio, la búsqueda de autonomías y el establecimiento de nuevas relaciones entre la sociedad y la naturaleza. territarias 31

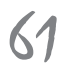


Con la intención de recoger aportes de las diversas perspectivas, podemos plantear un abanico de elementos necesarios para describir y analizar la acción colectiva contenciosa, no todos ellos abordables en el contexto de este trabajo. El mapa conceptual de la figura 1 presenta dicha síntesis. Hay tres temas en ese mapa conceptual.

En primer lugar, está la cuestión de la formación de un sujeto dispuesto a participar o iniciar acciones colectivas contestatarias. Ese sujeto politizado no se entiende sin la conciencia acerca de la existencia de conflictos enraizados territorialmente, dis- tribuidos o construidos desigualmente. Por su parte, la conflictualidad no es un 'dato' independiente de la identidad, el arraigo y el sentido de lugar. Los conflictos, la conciencia de estos, los actores y sus posiciones en el marco de una confrontación política no se pueden separar de la existencia de unos sentimientos, valores, costumbres y visiones derivados de vivir en un lugar particular. Estos ayudan a caracterizar los supuestos culturales compartidos sobre los cuales surgen y se amarran las redes de individuos u organizaciones sociales que despliegan acciones concretas para reivindicar derechos

Figura 1. Dinámica de la acción colectiva contenciosa

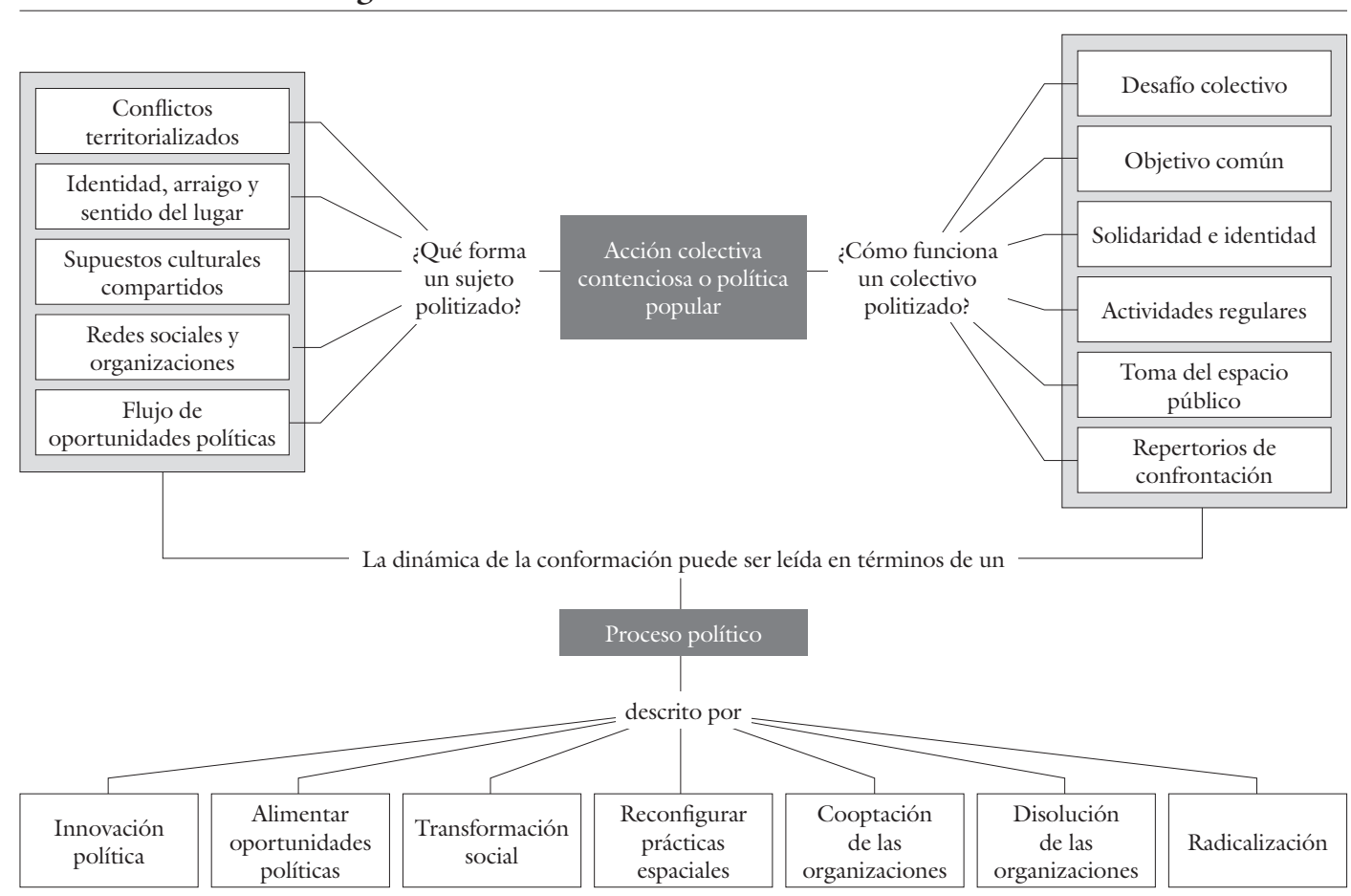

Fuente: elaboración del autor. 
o visibilizar problemáticas. Las redes son el soporte, el vehículo y el resultado de la acción colectiva contenciosa.

Sin embargo, estas redes, la conciencia de conflictos, la politización del sentido de lugar y la identidad requieren un ambiente político propicio que defina las oportunidades políticas para la acción colectiva contenciosa. Este marco de oportunidades, comúnmente llamadas estructura de oportunidades políticas, se refiere a una configuración cambiante de las condiciones institucionales, políticas, económicas y sociales que sirven de catalizadores de la política popular (Tarrow, 2011; Tilly \& Tarrow, 2006). Pero no se trata de algo externo que se impone a las redes sociales o a los individuos y que les permite automáticamente llevar a cabo acciones contenciosas. Más bien se trata de la apropiación social de términos, instrumentos y medios de ese variable ambiente sobre la base de la identidad, el arraigo, las construcciones sociales del conflicto y las redes sociales. Eso quiere decir que no todos los grupos ni todas las condiciones generan mecánicamente condiciones para la movilización social. Debido al carácter variable de la configuración de condiciones propicias para la acción contenciosa y de que son los grupos enraizados en lugares específicos los que apropian medios para la acción, nosotros usamos la expresión flujo de oportunidades politicas para referirnos a este elemento de la formación de actores politizados.

En el tema dos, en el mapa conceptual, está la cuestión acerca de cómo funciona y qué le da permanencia a la acción colectiva contenciosa, lo que permite distinguir la acción colectiva contenciosa de otro tipo de manifestaciones episódicas de 'lo colectivo', tales como motines, levantamientos, cierres de vías, tomas de plazas. En efecto, la acción colectiva contenciosa requiere acciones regulares, que permanecen durante algún tiempo en un lugar determinado y que den cuenta de la existencia de una organización social que es capaz de ver un desafío, construir unos objetivos comunes $\mathrm{y}$, al mismo tiempo, fortalecer-crear identidad. Resulta clave entonces la existencia de actividades regulares de la organización destinadas a discutir problemas barriales, la creación de acuerdos, distribución de tareas, definición de un nombre para la organización y, muy importante, la adopción y confección de un repertorio de confrontación, es decir, el conjunto de actividades concretas destinadas a transmitir públicamente (a la comunidad, al 'Estado', a los medios de comunicación, a la comunidad nacional e internacional, a las mafias, a la delincuencia organizada) un mensaje referente al menoscabo, limitación o afrenta a derechos particulares. El trabajo con las organizaciones sociales mostró, además, que las actividades concretas de las organizaciones, el repertorio de confrontación, derivan, entonces, de la pregunta sobre cómo visibilizar un problema, cómo tomarse el espacio público y cómo introducir significados y valores para transformar un estado de cosas juzgado como intolerable, vejatorio o injusto en relación con unos derechos de referencia.

En tercer lugar, está la cuestión sobre la trayectoria subsiguiente que toma la territarias 31

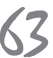


acción colectiva contenciosa, el proceso político que desencadena la política popular y la diversidad de caminos adoptados por las organizaciones. Estos caminos se presentan como preguntas acerca del futuro y el impacto social del trabajo de las organizaciones, pero, sobre todo, interesa la innovación política (entendida tanto como creación de instancias de relacionamiento interpersonal alternativo, así como dinamizador de las políticas públicas) que generan las acciones de las organizaciones. Esa innovación política efectuada por las organizaciones sociales implicaría, entonces, introducir cambios en cómo el Estado interviene en temas específicos, en las prácticas y apropiaciones cotidianas de los espacios de las personas, en el proceso general de transformación de la sociedady, por supuesto, en alimentar el caudal de oportunidades politicas para otros individuos o comunidades aún no organizadas.

La radicalización de las organizaciones sociales puede ser un posible camino del proceso político de la acción colectiva contenciosa. Pero también puede darse el caso de la disolución a raíz de múltiples peleas internas (por dinero, sentimentales, competencia por liderazgos), ruptura de acuerdos básicos, diferencias sobre el nivel de compromiso o radicalización de las actividades de las organizaciones, etc. $\mathrm{O}$, por último, se puede dar el caso de la cooptación de las organizaciones sociales por parte de actores como 'el Estado', burocracias armadas y partidos políticos, con medios y recursos suficientes para la incorporación

\section{territarias 31} 64
Este tercer componente suscita debates que expresan los presupuestos epistemológicos a partir de los cuales se juzga la utilidad, validez o pertinencia de las acciones colectivas contenciosas. Esos presupuestos epistemológicos, por lo general, usan algún tipo de denominador que sugiere progresión o desmejora en el proceso político y derivan en una jerarquía normativa o clasificatoria de las acciones de las organizaciones sociales. La mayoría de esas clasificaciones son esencialmente etnocéntricas y usan como referentes condiciones y procesos políticos locales constituidos en patrón universal, y, además, suelen descalificar de entrada este tipo de acciones nucleares, porque las consideran irrelevantes, porque no hacen parte de una 'vanguardia', porque no tienen un discurso 'clasista', porque no hacen parte de un partido, porque no 'definen bien' democracia o territorio o memoria, porque son pacifistas, etc.

Siguiendo a Enrique Dussel, hay que estar abiertos y ser críticos para observar la complejidad de las acciones que de manera pluriforme las organizaciones sociales llevan a cabo. Esto implica, básicamente, no replicar ni partir de los supuestos moderno-coloniales tanto liberales como los del socialismo real a la hora de catalogar estas acciones (Dussel, 2006). Esta aclaración es necesaria porque las organizaciones sociales que efectúan proyectos no autoritarios y basados en la profundización o reivindicación de derechos están llenas de diversidad y se forjan en una matriz cultural precisa (por ejemplo, patriarcal, religiosa, de competencia, egoísmos, etc.), por lo que po- 
drían aparecer múltiples 'contradicciones' o 'incoherencias' si se juzgan con el racero de un marco universal sobre lo que es válido y lo valioso de una actividad política.

\section{Territorialización de las acciones colectivas contenciosas para promover la convivencia y la seguridad en Bogotá}

En esta sección, se aborda la acción colectiva contenciosa en dos niveles: a) en primera instancia, el nivel de las acciones colectivas en la localidad Ciudad Bolívar en Bogotá y b) a la escala de un tema en un proyecto en el barrio Los Libertadores, en la localidad de San Cristóbal. ${ }^{4}$ Se trata básicamente de introducir una descripción espacial de la acción colectiva contenciosa haciendo énfasis en las redes tanto de acciones como de actores que participan en esta. Esto permite hacer énfasis en la importancia que tiene la descripción de la territorialización de la política popular para conocer fenómenos y formular preguntas que las teorías predominantes sobre la acción colectiva no se plantean.

\subsection{El proceso político popular visto territorialmente en Ciudad Bolívar}

La formación física y social de Ciudad Bolívar está acompañada y produce un mundo político 'local' que algunos trabajos han narrado parcialmente (Alape, 1995; Herrera \& Chaustre, 2012; Mantilla, 2007; Zibechi, 2008). De sus relatos y las conversaciones con miembros de organizaciones, se pueden encontrar cuatro fases de este proceso de la movilización social en esta localidad y la manera como se ha enraizado territorialmente.

La primera fase, en la década de 1980 , se caracteriza por un relevo (no desaparición) del protagonismo de los movimientos insurgentes (M-19, principalmente) como movilizadores sociales de la localidad como producto de la ascendencia de las primeras iniciativas organizativas de jóvenes en Ciudad Bolívar (Alape, 1995). Esto se combina con el fortalecimiento de juntas de acción comunal y organizaciones civiles variadas que luchaban por acceso a la vivienda, servicios públicos y bienes de consumo colectivo. Surgen en San Francisco, Jerusalén, Compartir, Juan Pablo II, Arabia y La Estrella, basadas en iniciativas culturales, de comunicación y de defensa de los derechos humanos. Aparecen organizaciones como el Comité Juvenil Arabia, El Club Deportivo Juvenil San Francisco, El Colegio Técnico San Francisco, El Comité Juvenil Nueva Argentina, Semillas Creativas y Juana de Arco. Estos barrios serán escenario de las primeras muertes y masacres de jóvenes, razón por la cual las organizaciones fueron instituyendo en su desafío común la bandera de la lucha por la garantía y respeto a la vida (Herrera \& Chaustre, 2012; Mantilla, 2007).

La segunda fase, comienzos de la década de 1990 hasta 1995, se caracteriza, primero, por el tránsito de la idea de los jóvenes como víctimas-victimarios a la de los jóvenes como sujetos innovadores con propuestas y prácticas valiosas. Segundo,
${ }^{3}$ Se basa en algunos datos del proyecto "Análisis de redes sociales como fundamento estratégico para la formulación y estructuración de la Red Distrital de Reconciliación, Resistencia Civil y No Violencia en la localidad de Ciudad Bolivar", en el que participó el autor. La investigación fue desarrollada por el Centro de Investigaciones sobre Dinámica Social (CIDS) de la Universidad Externado de Colombia en 2006 y dirigida por el sociólogo Álvaro Toledo.

${ }^{4}$ Se basa en la información recolectada para la tesis doctoral del autor titulada Estrategias y prácticas de securitización en la producción del espacio urbano. Los datos de campo son del año 2011.

territarios 31 
por la politización del sentido de pertenencia a la localidad sobre la base de impulsar acciones para mejorar las condiciones de convivencia entre jóvenes, de donde surge como desafío común la creación de territorios de afecto destinados a sanar las rivalidades entre grupos y refrendados en diversos festivales juveniles. Tercero, por la creación de lazos con instituciones gubernamentales y no gubernamentales a través de la financiación de proyectos (Mantilla, 2007). Zibechi señala que un hito en la creación de oportunidades políticas en este período fue la creación de una asociación de 65 organizaciones de Ciudad Bolívar llamada Unidad Cívica (1993), que convocó un paro cívico exitoso, el cual derivó en inversiones estatales en infraestructura educativa y servicios públicos (Zibechi, 2008; Mantilla, 2007).

En la tercera fase, se da un aumento del caudal de oportunidades políticas a través de la extensión de los liderazgos juveniles (1995 a 2003). Las organizaciones se preocupan por formar líderes, por construir infraestructuras para estas y por estrechar los vínculos entre organizaciones y con las instituciones gubernamentales y no gubernamentales; todo esto transversalizado por los temas de derecho a la vida y la no violencia. Se da un estrecho vínculo entre procesos políticos populares y los proyectos culturales (teatro, artes plásticas, música, comunicaciones, etc.). Se crean los concejos locales de cultura y los concejos locales de juventud, nace la Mesa Minga, Asodic Siglo XXI, que propone la creación de 'núcleos organizativos zonales', y Red Juvenil e Infantil de Promotores de DD. HH., donde se encuentran organizaciones sociales con instituciones estatales y no estatales, y se posicionan temas como derechos humanos, productividad, memoria y territorio (Nieto, comunicación personal, 2014).

En la cuarta fase, hay un socavamiento de oportunidades políticas a través del ataque sistemático a las organizaciones sociales desde 2003 hasta la actualidad. Con la expansión del paramilitarismo en las ciudades desde 2003, se recrudece la persecución y exterminio físico de líderes de organizaciones (Zibechi, 2008). De ahí que las organizaciones sociales fortalezcan el discurso político alrededor del no olvidar los asesinatos de líderes y jóvenes (memoria) como un mecanismo para evitar el control militar o armado de sus espacios de vida cotidianos (territorio). En esta fase, derecho a la vida, memoria, territorio y antimilitarismo son los términos que más se involucran en las acciones y proyectos de las organizaciones (Tabares, comunicación personal, 2014). Se llevan a cabo movilizaciones a favor del derecho a la vida, como, por ejemplo, la movilización de 2004 llamada "Para seguirle la línea a la vida" ("Para seguirle la línea a la vida”. Documental sobre la movilización de 2004 en Bogotá, 2008), la movilización de 2005 titulada "Para que la vida siga siendo joven" (Red de Hermandad y Solidaridad con Colombia, 2005) y el Mandato por la Vida impulsado por la Red Juvenil e Infantil de Promotores de DD. HH., a la cual nos referiremos posteriormente. Todas estas acciones buscaron visibilizar el riesgo de las organizaciones y la 
insistencia por hacer de Ciudad Bolívar un territorio de paz a través de acciones colectivas no violentas y fortaleciendo el tejido social desde los principios de solidaridad.

Esto permite comprender los procesos que han formado el conjunto de organizaciones que describimos espacialmente a continuación. Partimos de un dato despreciado en las ciencias sociales, el de la georreferenciación de una base de datos, la cual está compuesta por 182 organizaciones sociales que dicen trabajar por la convivencia y contra la violencia, para problematizar la distribución espacial de las organizaciones y las redes que estas crean. Miraremos que la relevancia de esto tiene que ver con la posibilidad de plantear preguntas más aterrizadas sobre los procesos políticos. Veamos.

Como es de esperarse, existe un desarrollo desigual de las organizaciones en la localidad de Ciudad Bolívar, donde varían las densidades y donde aparecen lugares con alta concentración de estas (ver figura 2). Las UPZ ${ }^{5}$ San Francisco y Arborizadora tienen la densidad más alta de organizaciones. Esto se relaciona con la existencia de un patrón de distribución en el que existen focos de concentración que de algún modo son los centros de comando de política popular en Ciudad Bolívar. Existen cuatro concentraciones de organizaciones en Ciudad Bolívar: a) la conformada por Arborizadora Alta y Baja y Candelaria La Nueva, que es la más importante; b) la que está entre los barrios Quiba, Paraíso y El Mirador; c) la que está en los barrios San Francisco y Las Acacias; y d) el foco que está en los barrios
Santa Viviana, Santo Domingo y Potosí. Alrededor de estos núcleos, las organizaciones sociales están dispersas casi homogéneamente, exceptuando las partes altas y rurales de la localidad, donde la presencia de organizaciones es muy baja.

Estos lugares donde se concentran más organizaciones sociales parecen ser sitios donde se incuban organizaciones y donde existe más diversidad, oportunidad o recursos. Los datos muestran que allí donde hay más organizaciones y más densidad de ellas hay mayor diversidad de propósitos dentro del gran objetivo de promover la convivencia y la erradicación de la inseguridad. Esto quiere decir que en un núcleo de organizaciones no existe un monopolio de temas, sino, por el contrario, que la concentración promueve oportunidades para la diversificación de las organizaciones. En efecto, allí donde hay un número de organizaciones más alto la distribución de los propósitos es más o menos homogénea comparada con aquellos lugares donde hay menos de estas.

Las 182 organizaciones dicen tener un poder de convocatoria cercano a las 85.000 personas en una localidad que tiene alrededor de 800.000 habitantes, un dato que habla sobre su presencia territorial. De acuerdo con los datos aportados por las organizaciones, la convocatoria promedio de estas es de 491 personas (Peña, 2011). La UPZ donde la relación entre el número de organizaciones y convocatoria es más alta es en El Tesoro, en el cual existen 7 organizaciones que dicen convocar 7.884 personas, es decir, 1.126 personas cada una. Paralelamente, la UPZ donde la relación
Unidades de planeación zonal. Son divisiones administrativas dentro de las localidades. Estas últimas, a su vez, son divisiones dentro de la jurisdicción de Bogotá.

territarias 31

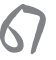


Figura 2. Localización y distribución de las organizaciones sociales en Ciudad Bolívar

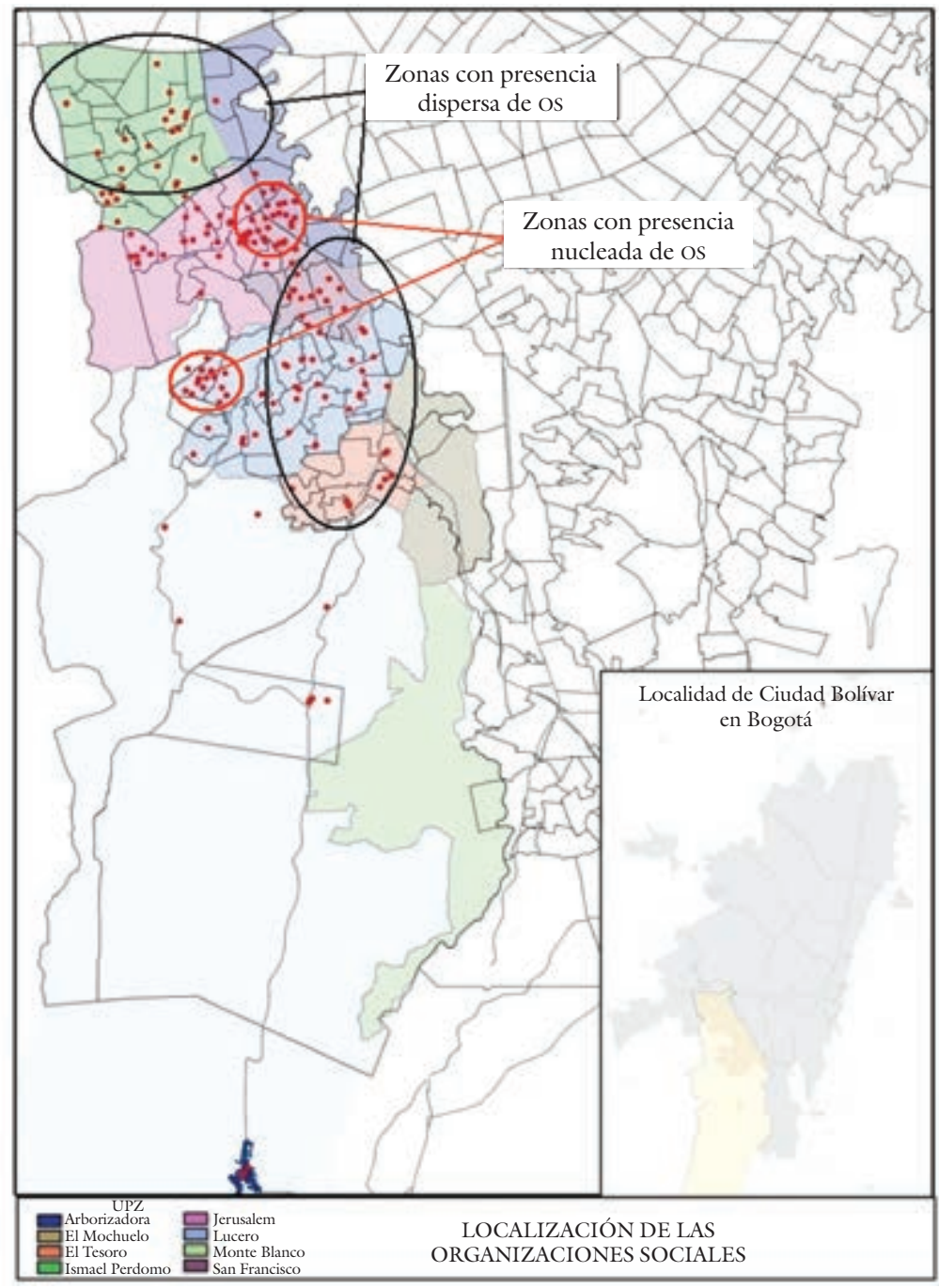

Fuente: Peña, L. (2011). Algunos elementos metodológicos para pensar espacialmente en ciencias sociales. Universidad Externado de Colombia, CIDS.

\section{territarias 31}

convocatoria-número de organizaciones es más baja es Jerusalén, pues hay 31 organizaciones con un poder de convocatoria de 9.665, es decir, cada organización, en promedio, convoca 312 personas cuando hacen algún tipo de actividad (Peña, 2011).

Las organizaciones sociales más grandes, como se aprecia en la figura 3, se en-

Figura 3. Relación convocatoria-número de organizaciones sociales. Priman os pequeñas y medianas con un poder de convocatoria amplio (85.000 personas)

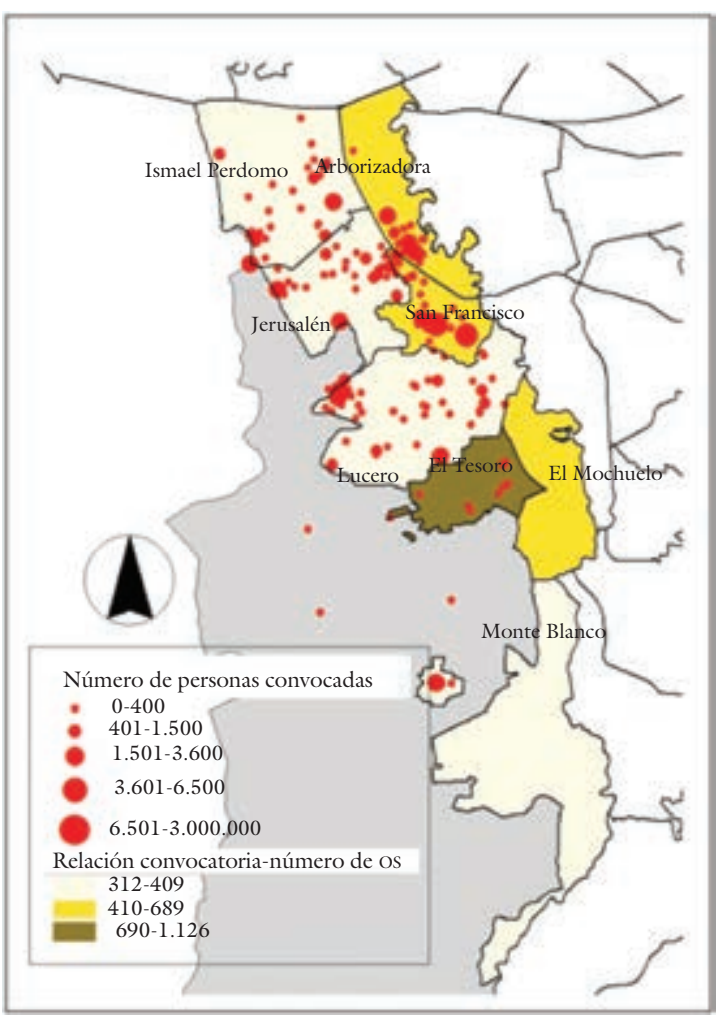

Fuente: Peña, L. (2011). Algunos elementos metodológicos para pensar espacialmente en ciencias sociales. Universidad Externado de Colombia, cIDs.

Luis Berneth PeÑa 
cuentran en las UPZ de Arborizadora y San Francisco, que son, a su vez, los sectores donde está un número importante de ellas. Por su parte, la UPZ Lucero, que posee la mayor cantidad de organizaciones $(50$, en total), expresa una relación entre el nivel de convocatoria con número de organizaciones baja: cada organización convoca 385 personas en promedio. Esto quiere decir que los lugares donde hay más diversidad de propósitos y más organizaciones sociales es donde el poder de convocatoria es menos voluminoso y viceversa, allí donde hay más pocas organizaciones y menos diversidad de propósitos están las organizaciones con más capacidad para convocar a la comunidad (Peña, 2011).

A los datos anteriores, referidos a la territorialización de la política popular, hay que sumarles el ámbito de acción en el que las organizaciones dicen moverse. El 69\% de estas tienen un espacio de acción predominantemente en el interior de la localidad, distribuidas de la siguiente forma: aquellas con espacio de acción localidad son el 35\%, el $20 \%$ son netamente barriales y el $14 \%$ tienen un espacio de acción que se limita a la UPZ donde se encuentran. Existe un conjunto de organizaciones multiescalares que representan el 9\%, que dicen trabajar desde el barrio hasta el país o, incluso, en el exterior. Aunque parece que no son un número importante, estas organizaciones pueden impulsar o fortalecer una red con lazos externos provechosos y también que impliquen retos para la acción colectiva.

Las organizaciones con espacio de acción más vecinal o microlocal son las que se encuentran en las UPZ de Mochuelo, Monte Blanco y Lucero, zonas altas de la localidad y donde la densidad de organizaciones es más baja. Contrariamente, las UPZ en las que las organizaciones dicen tener un espacio de acción más amplio son las de Arborizadora, San Francisco, Ismael Perdomo y Jerusalén, porque hay organizaciones que trabajan en toda la localidad y más allá de esta. Esto confirma que el núcleo de comando y de gestión de las organizaciones sociales y la red social se encuentra en estas UPZ, donde además priman, como lo muestra la figura 4 , organizaciones pequeñas y medianas. Las 16 organizaciones grandes (ver figura 5) no evidencian una tendencia tan clara como en el caso anterior porque su radio de acción va desde las netamente barriales hasta las de espacio de acción distrital a internacional.

Hay que decir que en estas zonas de comando con más densidad y diversidad de organizaciones es donde están las organizaciones que más salen a la calle y ejecutan más proyectos, y también el número de organizaciones que en el período de referencia (2005-2006) estuvieron más inactivas. Mientras que, en las zonas altas con menor densidad de organizaciones, está el número de organizaciones menos activas en la calle pero más activas ejecutando proyectos (hacer historias barriales, participar en investigaciones y consultorías, realizar diagnósticos).

Otro tema de la territorialización de la acción colectiva contenciosa tiene que ver con las redes que resultan de realizar proyectos o acciones conjuntas. En la figura 6 , territarias 31 

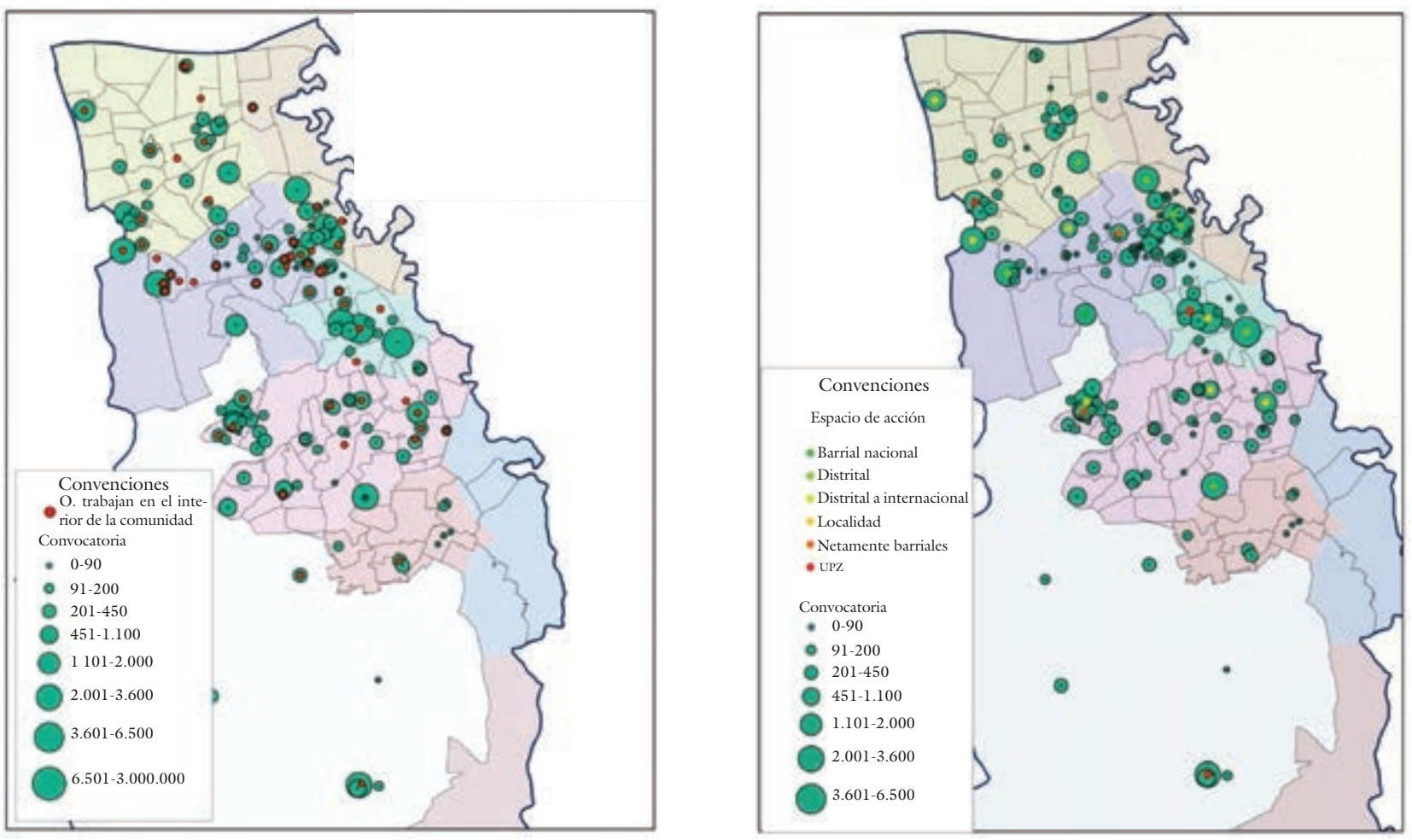

Fuente: Peña, L. (2011). Algunos elementos metodológicos para pensar espacialmente en ciencias sociales. Universidad Externado de Colombia, CIDS.

${ }^{6}$ De las 182, 83 organizaciones llevaron a cabo acciones conjuntas.

\section{territarias 31} 70 que muestra los vínculos entre las organizaciones ${ }^{6}$ y el tamaño de la organización (puesta en términos de su capacidad de convocatoria), se representa cartográficamente esta red partiendo de la localización de las organizaciones y de la información sobre los vínculos entre estas. Esta representación permite tener una descripción territorializada de las redes de acciones contenciosas y, de paso, dejar de lado los tradicionales grafos abstractos empleados en los análisis de redes en los que la política popular no está en relación con su lugar de acción. Veamos.

La figura 6 muestra lo problemático que resultan las relaciones entre organizaciones vecinas. Ya se vio que la cercanía propicia diversidad, pero también disminuye la capacidad de convocatoria de las organizaciones. Sin embargo, aquí las or- 
ganizaciones sociales comparten acciones con las organizaciones que están por fuera de su ámbito más próximo (barrio y UPZ). Si se diera el caso en el que primaran las relaciones basadas en la vecindad, las líneas de conexión serían, predominantemente, más cortas. Este dato es coincidente con conversaciones que el autor sostuvo posteriormente con las y los líderes de las organizaciones, quienes suelen tener algunas controversias o desconfianzas con las y los líderes de organizaciones más próximas.

Este mismo mapa también demuestra, además, que las organizaciones más pequeñas son las que sirven de eje de la red. Los puntos donde converge la red de relaciones hacen referencia a aquellas con menor poder de convocatoria y, contrariamente, donde hay organizaciones con mayor convocatoria no llega prácticamente ningún lazo de conexión. Podría pensarse que la 'lógica' en este rasgo de la red es que, entre más grande sea la organización, menos necesidad tiene de asociarse y viceversa. No obstante, desde el punto de vista del análisis de redes, una organización social grande que lleva a cabo proyectos o acciones conjuntas potenciaría la influencia de la red en el conjunto de la sociedad.

Esta descripción de la territorialización de la política popular en Ciudad Bolívar permite obtener dos resultados. El primero es una serie de preguntas aparentemente simples, que no pueden ser planteadas sin tener en cuenta el despliegue espacial de las organizaciones y sus redes, sobre proceso político popular en Ciudad Bolívar. ¿’Por qué en ciertas zonas hay una presencia
Figura 6. Red de acciones compartidas por las organizaciones sociales de Ciudad Bolívar (2005-2006)

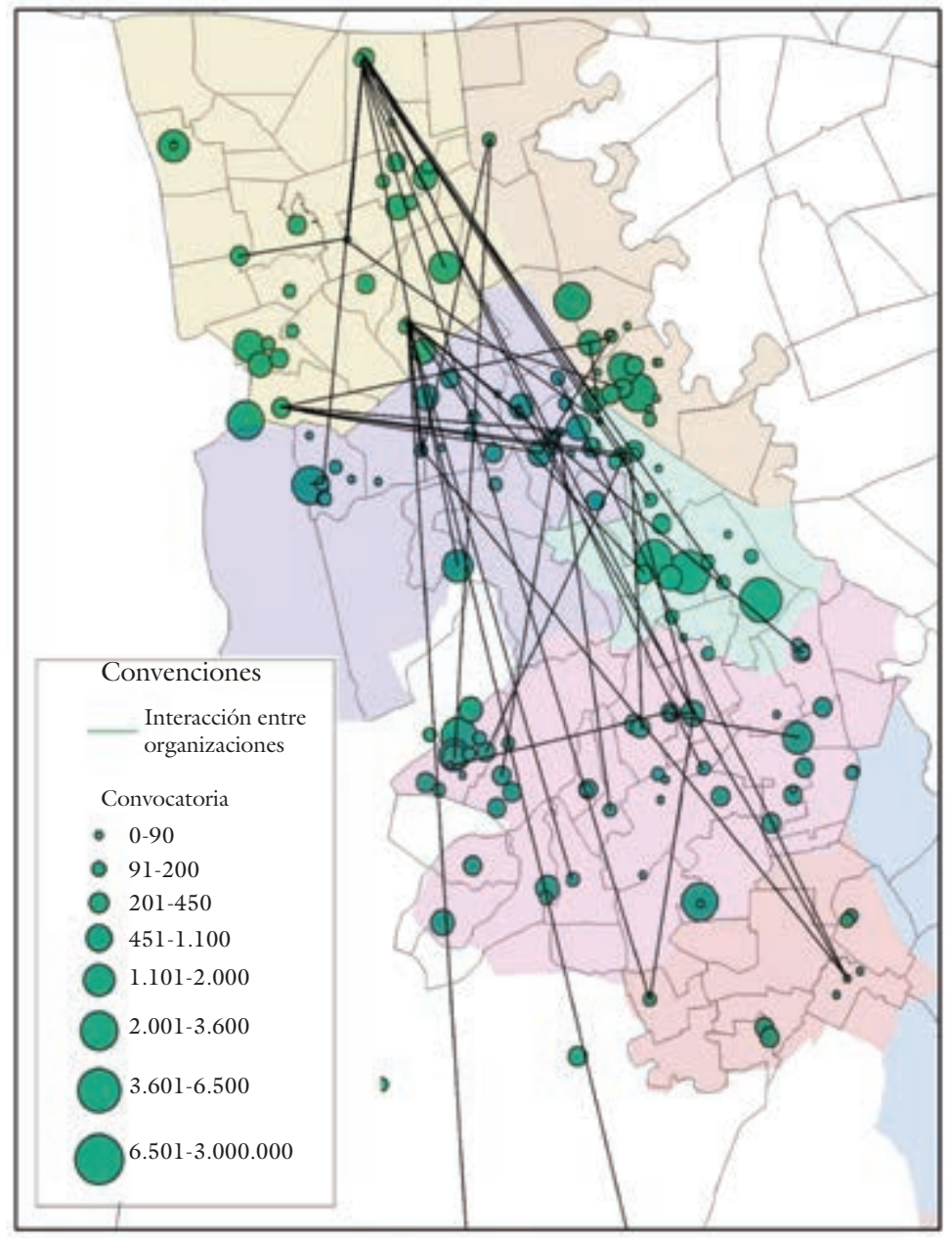

Fuente: Peña, L. (2011). Algunos elementos metodológicos para pensar espacialmente en ciencias sociales. Universidad Externado de Colombia, CIDS.

más alta de organizaciones sociales y qué pasa allí donde no hay? ¿Por qué donde hay más densidad de organizaciones hay menos proyectos pero las organizaciones territarias 31 
Figura 7. Síntesis de la estructura espacial de las organizaciones y retos diferenciados para la construcción de redes para la acción colectiva contenciosa

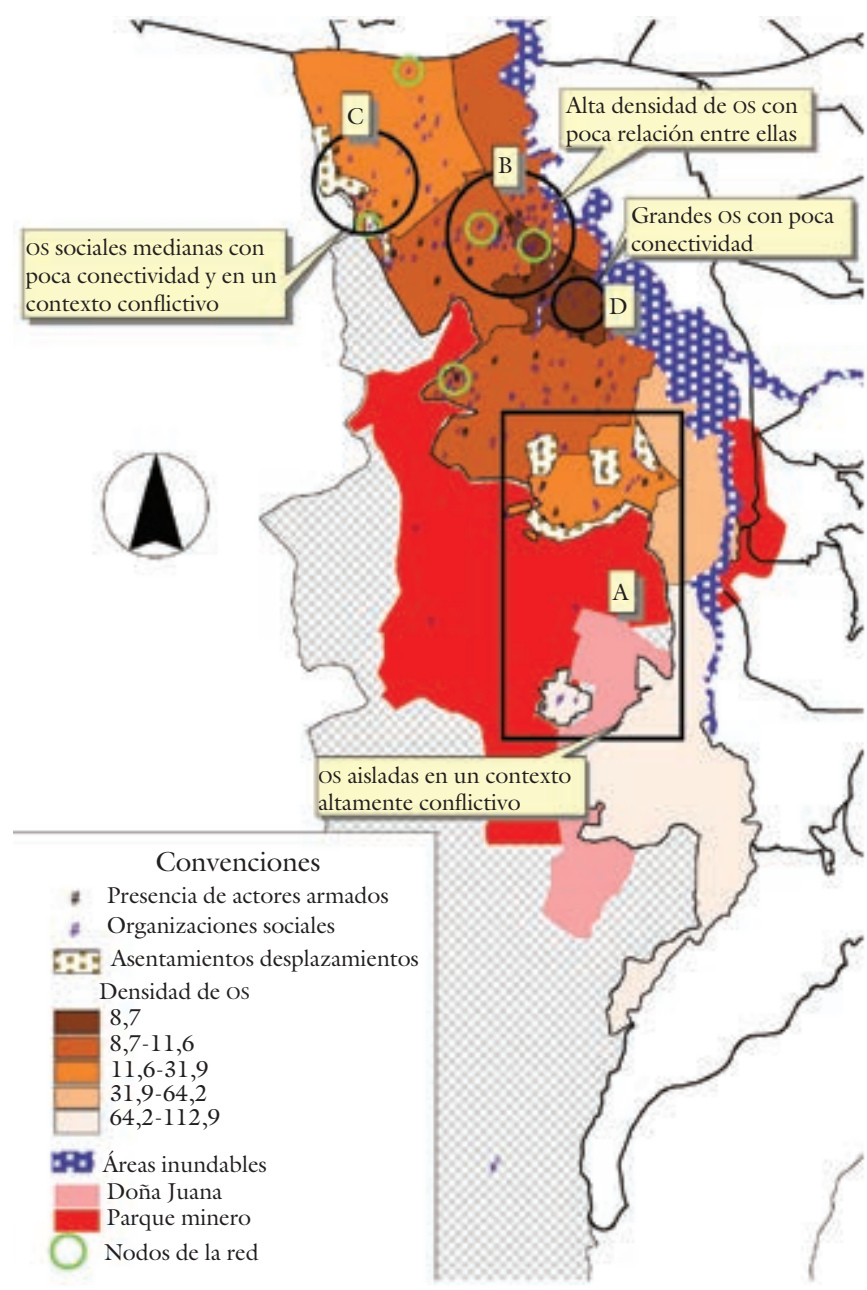

Fuente: Peña, L. (2011). Algunos elementos metodológicos para pensar espacialmente en ciencias sociales. Universidad Externado de Colombia, CIDS.

\section{territarias 31} 72 salen más a la calle y, en cambio, allí donde las organizaciones son menos numerosas hay más proyectos y menos actividades en la calle? ¿Tiene que ver con una suerte de maduración de las organizaciones? ¿Qué nos dice esto sobre la distribución de oportunidades políticas y constreñimientos a la política popular o sobre la cooptación de las organizaciones? $\mathrm{O}$ ¿acaso las organizaciones sociales más aisladas tienen más restricciones para efectuar actividades públicas? ¿Qué pasa en los lugares donde las organizaciones se juntan con otras organizaciones? ¿Operan estas en lugares con alta presencia de grupos armados o se trata de organizaciones cooptadas por el Estado y ONG? En últimas, estas cuestiones ayudan a problematizar el desarrollo desigual de las oportunidades y constreñimientos políticos a la acción colectiva contenciosa.

El segundo resultado que se deriva de la descripción de la territorialización de la acción colectiva contenciosa es una síntesis de un momento del proceso político local que expresa la diversidad de situaciones que experimentan las organizaciones sociales y las redes sociales en la localidad. La figura 7 expone esta síntesis compuesta de cuatro zonas:

La zona A, principalmente en las UPZ de Mochuelo y Monte Blanco, donde hay una baja densidad de pequeñas organizaciones débilmente conectadas con el resto de sus pares tanto dentro como por fuera de la localidad y con una grave problemática ambiental (minería, producción de ladrillo, depósito de basuras) de infraestructuras y presencia de grupos.

La zona B, en la convergencia de las UPZ San Francisco, Jerusalén y Arborizadora, se caracteriza por tener la más alta 
densidad de organizaciones sociales en la localidad, con dos grandes nodos de la red y una apreciable cantidad de pequeñas y medianas organizaciones, con muy baja conectividad entre ellas y con amenazas por inundación y presencia de grupos armados.

La zona C, en los barrios Santa Viviana, Santo Domingo, Potosí, entre otros, tiene una concentración de organizaciones medianas con muy poca conectividad y en un contexto de alta conflictualidad derivada del conflicto armado por la presencia de grupos armados y nuevos barrios con mucha población en condición de desplazamiento.

La zona $\mathrm{D}$ es una pequeña área de la UPZ San Francisco con organizaciones con alto poder de convocatoria en un lugar con alta densidad de organizaciones que no participan ni en acciones ni en proyectos. La conflictualidad en la zona D se evidencia en la presencia de grupos armados y en el riesgo por inundación del río Tunjuelito.

\subsection{La acción colectiva contenciosa}

\section{a la escala de un proyecto.}

UPZ 51 Los Libertadores, localidad de San Cristóbal

Como se ha visto, en el proceso que siguen las organizaciones, se establecen lazos no solo con otras organizaciones sociales, sino con múltiples instituciones de carácter nacional e internacional. Esos vínculos definen las posibilidades, los bloqueos o la subordinación a la que se expone la acción colectiva contenciosa. Para tal fin, se narra el caso del Programa Sur de Convivencia, que es un proyecto que busca promover la seguridad y la convivencia a través del mejoramiento integral de los barrios. Es un proyecto que tiene sede en la Secretaría de Hábitat del distrito con una financiación importante del Instituto Alemán de Crédito para la Reconstrucción (Kreditanstalt für Wiederaufbau, KfW) y con la participación de organizaciones sociales de San Cristóbal. ${ }^{7}$ La gestión del proyecto la hace el Centro de Reconciliación del barrio Los Libertadores, que es uno de los centros creados por la Fundación para la Reconciliación en Colombia. Estos centros de reconciliación son financiados por entidades diferentes. El del barrio Los Libertadores lo financia la Secretaría Distrital de Hábitat y el KfW.

Esta composición es diciente de la manera en la que las organizaciones sociales se mueven en los proyectos. Estas están rodeadas de actores disímiles y con propósitos diversos que siempre tienen más recursos que ellas, lo que les impone a las organizaciones el reto de negociar constantemente entre sus principios, su autonomía y su compromiso, con los beneficios que pueden resultar en términos de promover cambios que buscan visibilizar su trabajo, conseguir recursos para la organización y crear redes con otras organizaciones. Si bien hay muchos casos donde las organizaciones son reacias a trabajar con oficinas del Estado o con instituciones internacionales, la actitud que encontramos en este proyecto es la de la confianza de las organizaciones en el proyecto y los demás participantes. La desconfianza de las organizaciones está
Esta es la lista de participantes en el proyecto: SIE, corporación ambiental; Fundación Creciendo Unidos; Tertulia Pedagógica Zona 4E; Corporación Ambiental Chilcos; Loma Sur Red de Comunicadores y Comunicadoras de San Cristóbal; Red de Actores Sociales de Convivencia Ciudadana AVCC; Idipron; Siglo XXI; Contexto Urbano Fútbol por la Paz; Grupo de Mujeres; Organización Musical Momo; Banca de Proyectos; Arto Arte; Corporación Mujeres Unidas de San Rafael; Fundación Social y Deportiva Semilleros de Convivencia (Ramelsa).

\section{territarias 31}

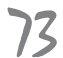


${ }^{8}$ En las visitas de campo, en losencuentros informales con funcionarios y miembros de organizaciones, era muy frecuente encontrar comentarios relativos a los valores comúnmente asociados con las instituciones alemanas: "Hay que cumplir con los plazos porque usted sabe cómo son los alemanes", "No se puede salir con cualquier cosa porque los alemanesson cuadriculados", "Ellos trabajan como relojitos”, etc.

\section{territarias 31}

dirigida más bien hacia los que buscan acercarse a ellas con el fin de conseguir votos. Un líder de la Asociación Siglo XXI sostenía: “Claro que sentimos prácticas clientelistas y politiqueras en acompañamientos a ciertos liderazgos de parte de algunas instituciones. Esa es política vieja. Pero sabemos que hay nuevas instituciones que generan espacios de encuentro que nos permite hacer trabajo de campo a las organizaciones y eso nos da una ventaja de discurso frente a las mismas entidades que ya han aprendido a respetarnos y nosotros a ellas" (Asociación Siglo XXI, Jorge, 2011).

Las organizaciones que participan en un proyecto como este parecen reconocer que el Estado no es un actor unitario, porque dentro de este hay profundas disputas, lo que les facilita entrar en relación con oficinas gubernamentales y, en general, con otros actores. Con la cooperación internacional, hay menos matices y se suele olvidar que la cooperación no es altruismo puro, ya que el cooperante se pone en una situación jerárquicamente diferente a la de quien recibe y existe un campo relacional asimétrico, donde no queda ambigüedad sobre quién debe aprender de quién. ${ }^{8} \mathrm{Se}$ olvida que la cooperación reporta, entre otros beneficios para el cooperante, ventajas simbólicas para este.

No obstante, en medio de eso, las organizaciones encuentran posibilidades de promover proyectos comunes e independientes para combatir problemas de convivencia e inseguridad. Dentro de ellos está la Iniciativa Comunitaria por la Paz, la No Violencia y la Convivencia, que consiste en una serie de actividades y en el establecimiento de una agenda que apunta a repercutir en las políticas públicas de seguridad y convivencia para desencadenar dinámicas de paz en el territorio. Esta propuesta se basa en las experiencias de las organizaciones durante más de quince años y que han demostrado ser efectivas para dotar al territorio local de espacios públicos para convivencia y resistir al descuido histórico del Estado (Asociación Siglo XXI, Jorge, 2011).

En dicha iniciativa, hay cinco líneas de acción, que muestran la manera como las comunidades construyen perspectivas alternativas sobre seguridad urbana: a) la cultural y artística; b) la de educación no formal; c) la de creación y deporte; d) la de productividad y seguridad alimentaria; y e) la de medio ambiente. El primer cometido de la Iniciativa Comunitaria es hacer diagnósticos técnicos sustentados en procesos pedagógicos, lecturas puntuales y en diálogo con la comunidad, con el fin de presentarlos en un foro por la convivencia, acompañados de las instituciones del distrito, con las cuales se firmará un pacto que implica que los diagnósticos sean tomados en cuenta en los cabildos y presupuestos participativos. La Iniciativa también realizará comparsas, mercados de productos cultivados por la comunidad y unos recorridos para inscribir hitos de paz en los lugares que los diagnósticos nos muestran como los más problemáticos.

Este parece ser un caso en el que las redes de organizaciones y su vínculo con actores no comunitarios han fortalecido 
la organización social. Sin embargo, no se puede pensar que en todos los casos las redes de acciones sean provechosas para que las organizaciones sigan construyendo desafíos y objetivos comunes, promuevan una agenda de actividades regulares independientes y usen las relaciones para fortalecer sus recursos. Como se ha visto, depende de una conjunción de factores que no se repiten en cada situación, razón por la que no se puede dejar de lado el lugar donde los procesos políticos populares se desarrollan.

\section{Repertorios de confrontaciones en las acciones colectivas contenciosas a favor de la convivencia}

Aquí se narra algo del repertorio de confrontación de las organizaciones. Como se dijo, los repertorios de confrontación se refieren a las actividades concretas que desarrollan las organizaciones sociales para hacer visible una problemática, transmitir un mensaje públicamente y generar apropiaciones espaciales que desafíen la geografía de la inseguridad. Entre las acciones que se detectaron en el trabajo con las organizaciones, están, por ejemplo, foros de debate, performances, representaciones de obras de teatro, conciertos de rap y hip hop, caminatas, cine foros, embellecimiento de espacios públicos, carnavales, pintar murales-grafitis, lectura pública de poemas referidos al derecho a la vida, instalación de monumentos, instalación de placas recordatorias. Hay que decir que las acciones dentro de la acción colectiva contenciosa nunca son acciones puntuales y que se conectan con un conjunto de actividades de las organizaciones. También, es preciso saber que las acciones que narramos no son necesariamente exclusivas de una organización y reconocemos que las organizaciones tienen versiones diversas sobre cada una de las acciones que describiremos, porque no están de acuerdo sobre quién o qué grupo diseñó la acción y la empleó por primera vez.

\subsection{Pacto por la vida}

Esta fue una acción destinada a crear un mandato popular y un compromiso comunitario por la vida, y que se desarrolló como una 'votación simbólica' en la localidad de Ciudad Bolívar. La Red Juvenil e Infantil de Promotores de DD. HH., una organización social que promovió activamente la formación de gestores de derechos humanos y la formación de redes de organizaciones, fue una de las protagonistas de esta acción. La Red Juvenil e Infantil de Promotores de DD. HH. desarrolló un trabajo, principalmente, en los centros educativos de la localidad, cuyos principales objetivos eran promover la cultura del respeto de los derechos humanos y construir liderazgos de jóvenes, niñas y niños (Red Juvenil e Infantil de Promotores de DD. HH., 2005).

El evento que motivó la acción fue el asesinato en 2005 en Ciudad Bolívar de una escandalosa cifra de jóvenes, unos 500, de acuerdo con las organizaciones de derechos humanos. A través de la recolección de firmas, apoyada por la Registraduría Nacional, 117.284 personas (de las 700.000 
que viven en Ciudad Bolívar) votaron por un mandato para hacer de Ciudad Bolívar un territorio de paz que decía lo siguiente:

Los jóvenes ¡nos declaramos desertores! y enemigos de la muerte, de la muerte a mano armada, de la muerte entrenada, de las balas disparadas, de la violencia organizada y no organizada. ¡Nos declaramos prófugos! De los cerebros bien lavados, de la paz con muerto $\sin$ nombre, de las armas por encima del hambre. ¡Nos declaramos amantes de la vida! Nos declaramos defensores de los derechos humanos, y del desarme, constructores de la cultura de no violencia (Peña, M. 2008).

En los años siguientes, las cifras de homicidios bajaron, pero siguieron siendo muy elevadas. En 2006, se registraron 126 homicidios. Esta acción le permitió a la Red Juvenil e Infantil de Promotores de DD. HH. participar en múltiples reuniones con autoridades y, además, convocar más jóvenes a la Red. En 2007, el alcalde Luis Eduardo Garzón se acercó a esta organización y creó una alianza con otros doce alcaldes del país para reglamentar el porte de armas.

Así, los integrantes de la Red Juvenil e Infantil de Promotores de DD. HH. de Ciudad Bolívar se convirtieron en ejes de una política de desarme en las demás localidades de la ciudad que les permitió promover otras acciones de éxito, tales como el Toque de Tambores por la Vida y el Desarme, la Cadena Humana por la Vida y el Desarme, y Nosotros También Tenemos Derecho a la Educación Superior (Nieto, 2014).

\subsection{Caminatas nocturnas contra los toques de queda y amenazas de grupos armados}

Aunque las caminatas son un tipo de acción frecuente en el repertorio de confrontación de las organizaciones sociales, aquí se destacan aquellas promovidas en la Mesa Local de Jóvenes como respuesta a los toques de queda impuestos por los paramilitares en su proyecto de extender su control territorial y social. La Mesa Local de Jóvenes, compuesta por varias organizaciones sociales y que cuenta con apoyos de la Secretaría de Gobierno de Bogotá y la alcaldía local de Ciudad Bolívar, se planteó construir memoria sobre las víctimas de la limpieza social ("No olvidar"), luchar contra la estigmatización ("Tenemos que vernos nosotros mismos de forma diferente") y promover la apropiación del territorio por parte de los habitantes de Ciudad Bolívar ("Somos territorio de paz y de vida").

Las caminatas se desarrollaron en diversos lugares (Arabia, Juan Pablo II, Perdomo, Perdomo Alto, Santa Viviana, Santo domingo, Potosí, Paraíso, Vista Hermosa, Arborizadora, Caracolí, entre otros) y buscaban el reconocimiento del entrecruce de varias geografías de la localidad (la geografía del miedo, la de las desigualdades, la de las formas de vida y la de la violencia) y retar la territorialidad paramilitar desobedeciendo su prohibición de salir a la calle en la noche (Tabares, comunicación personal, 2014).

\section{territarias 31}


Dentro del recorrido, se hacía alboroto, se hablaba, se cantaba, se iban presentando grupos artísticos, se hacían actos simbólicos, como, por ejemplo, poner una placa de recordatorio, tomarse las manos o dibujar en el suelo una silueta de una persona para señalar el lugar donde había sido asesinado alguien y con la consigna "No queremos más". La caminata terminaba en un canelazo o en una olla comunitaria, momento que era aprovechado para realizar la última actividad consistente en distribuir una hoja a los participantes preguntándoles dónde habían sentido más miedo, dónde se habían sentido más seguros, en qué lugar estuvieron más alegres, etc. A partir de eso, entonces, la Mesa de Jóvenes podía efectuar la evaluación de la acción con el fin de diseñar otras acciones en los lugares donde la gente tenía más miedo (Tabares, comunicación personal, 2014).

Las caminatas se convirtieron en una acción de mucho impacto en la localidad y las instituciones, además de apoyarlas parcialmente, también sacaban provecho de estas. Lo más frecuente, narrado por varios participantes, es que las instituciones llegaran a tomarse la foto en la caminata y a mostrar que esa actividad era resultado de sus proyectos. Esa ha sido una forma de cooptación del trabajo de las organizaciones y se expresa en la indignación que le produce a las organizaciones que 'el Estado' saque pecho con estas actividades y que sean ellos los que tienen que poner el pecho en su localidad a las amenazas cotidianas de los actores armados.

\subsection{Cuadras armónicas. Mural 'Vestigios de Humanidad'}

El colectivo Arto Arte de Los Libertadores ha hecho una serie de intervenciones que ellos denominan 'cuadras armónicas', basadas en la creación de murales en sitios clave y cuyo principal objetivo es motivar el diálogo entre vecinos acerca de problemas comunes (de convivencia, seguridades, derechos, ambiente, culturales, etc.) y sacar las discusiones sobre temas públicos de los espacios cerrados de oficinas para ponerlos en las calles. Este colectivo tiene un fuerte interés por promover la comunidad y consideran que en esta aspiración hay dos temas centrales: el espacio y las preguntas. Jesús David Suárez, miembro del colectivo Arto Arte, dice que él cree en el espacio y cree en las preguntas, es decir que cree que las intervenciones en el espacio público, visibles y palpables, tienen poder para generar preguntas sobre problemas comunes de las personas. "La pregunta común, la pregunta públicamente debatida y compartida es el comienzo de la comunidad. La intención es generar la acción, para luego ver las preguntas de la gente" (Suárez, comunicación personal, 2011).

El mural 'Vestigios de Humanidad', en el barrio Villa del Cerro, es una de estas acciones dentro de las intervenciones cuadras armónicas (ver figura 8). Esta obra tiene la particularidad, primero, de escoger una pared de una calle donde existan problemas de convivencia, seguridad, $y$, segundo, que se apoya en la comunidad porque usó dis- 
Figura 8. Mural 'Vestigios de Humanidad' recién terminado (enero 2012)

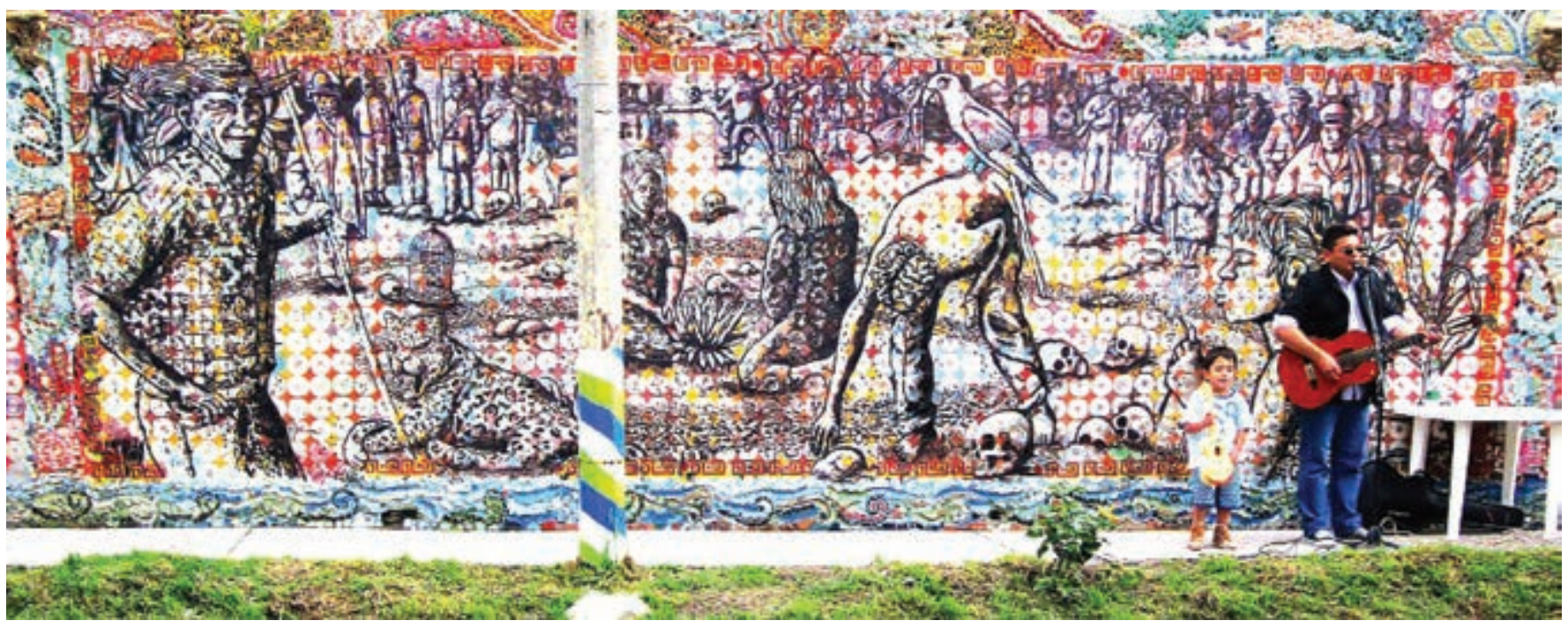

Fuente: página de Facebook del colectivo Arto Arte.

territarios 31

78 cos compactos y baldosas reciclados, aportados por la comunidad, sobre los cuales se pintó.

Las diferentes fases de esta acción tienen mucha riqueza, pero, curiosamente, la parte que más suscita el interés de esta intervención tiene que ver con su deterioro. Muchos discos compactos del ensamble pictórico ya no están en la pared y eso, de acuerdo con Arto Arte, es lo que permite hacer una evaluación del lugar donde la obra está jugando. "Pues justamente se trata de usar el deterioro del mural como una excusa para discutir los problemas del barrio. ¿Qué está pasando? ¿Por qué se está deteriorando? ¡Preguntémonos! El deterioro del mural no es un fracaso, de ahí salen las preguntas, como ¿qué hago yo para propiciar la protección de un espacio o de un objeto como estos?" (Suárez, 2012).

La filosofía de 'cuadras armónicas' es, entonces, promover encuentros de personas a través de objetos y espacios públicos intervenidos artísticamente. El mural no es, entonces, una pared intervenida por un grupo de artistas, sino, más bien, que actúa como un espejo de un lugar específico, de una comunidad y, si se quiere, de la sociedad donde la obra se instala, donde la obra cambia. En las reuniones que convocan organizaciones sociales o instituciones no populares para hablar de problemas como la seguridad, la gente va a quejarse y a pedir. Esta intervención cambia el foco y promueve que las personas reflexionen sobre sus propios hábitos cotidianos en los 
espacios más próximos. Esa es una innovación importante.

\subsection{Ollas comunitarias para combatir ollas de vicio}

Entre los diversos usos que tiene la olla comunitaria, llamó atención en el trabajo de campo una que narra óscar Benavides de la Corporación Comunitaria Cuyeca A Obsun, consistente en hacer ollas comunitarias allí donde funcionan las llamadas 'ollas de vicio', es decir, los lugares (puede ser una casa, una calle o un sector) donde funciona un expendio de drogas y desde donde se comandan muchos de los mercados ilegales que generan más criminalidad. La acción radica en que las organizaciones convocan una olla comunitaria cerca de la olla de vicio, con el fin de hacer presencia, usar el espacio público y promover la permanencia de las personas en esa zona. No hay manifestaciones en contra de la olla de vicio, ni arengas, ni carteles que manifiesten que la acción tiene que ver con la olla. Solo está la olla comunitaria como motivo para que la gente se tome la calle, una de las primeras cosas que pierde la comunidad cuando hay un poder mafioso ejerciendo control territorial y social.

La olla comunitaria está acompañada de múltiples actividades, tales como hacer juegos, tocar música, hacer bailes, performances artísticos o representar obras de teatro. El objetivo es extender las actividades y, por lo tanto, la presencia de las personas por el tiempo necesario para afectar el funcionamiento de la olla de vicio. Los consumidores de estupefacientes, que suelen ser vecinos, los policías corruptos que suelen participar de economías ilegales y los interesados en vender cosas robadas, dudan en visitar un sitio vigilado por la simple pero efectiva presencia de las personas. La efectividad de esta acción está demostrada en que los traficantes locales les han manifestado a los mismos participantes de estas acciones cosas como "Me voy de aquí porque ustedes no dejan trabajar" o "Ustedes se me tiraron el negocio" (Benavides, comunicación personal, 2011). La olla comunitaria se constituye así en la forma de reterritorializar las dinámicas de las comunidades a través de tomarse la calle. Esto recuerda el principio expuesto por Jane Jacobs en su clásico texto titulado El uso de las aceras, donde ella mostraba que la vigilancia más efectiva y no autoritaria es la que surge de usar las calles frecuentemente (Jacobs, 1961).

\section{Conclusiones}

Se han presentado acciones no autoritarias destinadas a la construcción de seguridad urbana teniendo como eje la acción colectiva contenciosa, las redes territorializadas de acciones y los repertorios de confrontación que despliegan las organizaciones sociales. Esto nos permite plantear cuatro puntos.

El primero es si estas acciones realmente sirven, si el trabajo de las organizaciones tiene impacto en la reducción de la criminalidad y si estas acciones son la solución a los problemas de seguridad. Lo primero, para reconocer la importancia de estas acciones contenciosas, es pensar que estas hacen territarias 31 
parte de un proceso político amplio. Las organizaciones no son ingenuas y saben que hay problemas que solo se resuelven haciendo cambios estructurales en la sociedad. Pero estas acciones están generando oportunidades e innovaciones políticas, y están diciendo que los cambios no les van a caer de afuera ni se construyen sin ellos o fuera de sus comunidades. Las organizaciones también entienden que sus actividades tienen un impacto en la seguridad, porque le quitan bases territoriales y sociales a la criminalidad, porque arrebatan jóvenes a los actores armados y les muestran opciones de vida alternativas basadas en valores como el estudio, el trabajo en equipo, la solidaridad y la bondad. Estas acciones han salvado vidas y han detenido el avance de actores armados, como lo muestra el caso del barrio Potosí, en el que las experiencias de educación comunitaria han logrado crear una contención a los grupos paramilitares que dominan en los barrios vecinos, como Caracolí.

En segundo lugar, con la presentación de estas experiencias se ha reivindicado que la política tiene un lugar (las organizaciones sociales usarán preferiblemente el término territorio) y, para tal fin, se habló de la manera como se territorializa, como se 'geografiza' la política, acudiendo a temas considerados poco problemáticos, como, por ejemplo, la distribución espacial de las organizaciones sociales y la estructura espacial de las redes de acciones. Pero, sobre todo, también se ha dicho que el lugar importa porque los conflictos, los desafíos, los discursos y las solidaridades están basados no solo en enraizamientos locales, sino en la reivindicación o construcción de sentidos de lugar alternativos a los impuestos por actores armados o por una cultura política basada en el sectarismo y la deshumanización. Los objetivos de las organizaciones están planteados efectivamente en términos de lucha contra representaciones espaciales hegemónicas que reproducen estigmas territoriales y estigmas sobre personas en las cuales hay que intervenir, corregir y disciplinar. Así, el lugar importa porque reivindicar o construir derechos (en los casos analizados, el de la vida) es básicamente territorializar derechos, lo que, en últimas, significa que la acción colectiva pone de manifiesto disputas entre actores por territorializar proyectos diversos. Después de esto, cobra sentido la pregunta: ¿qué quedaría de la acción colectiva contenciosa si suprimimos el espacio, el lugar o el territorio?

En tercer lugar, resulta extraño hablar de la seguridad urbana y la acción colectiva contenciosa porque existen prejuicios según los cuales las iniciativas destinadas a crear espacios más seguros son proyectos autoritarios o que la seguridad simplemente no es un derecho. La experiencia de trabajo del autor con las organizaciones sociales, justamente, contradice esos prejuicios, porque estas afirman que la seguridad es un derecho, aunque lo subordinan a la realización de otros derechos, y porque, con sus acciones, muestran que es posible innovar políticamente para promover formas no autoritarias de securitización de la ciudad. Adicionalmente, estudiar esta relación entre seguridad y acción contenciosa evidencia que 
la sociabilidad urbana basada en el miedo, el individualismo, la desconfianza y la exaltación de la violencia, está siendo retada y está lejos de ser unánime. Por eso, hablamos de una geografía de la esperanza, término ya usado por James Baer (1998) y David Harvey (2000) para referirse a los proyectos en los que las personas buscan ser arquitectos de un cuadro de vida alternativo. En nuestro caso, nos referimos a la geografía de la esperanza encarnada en los proyectos de construcción de una espacialidad alternativa a la violencia y la inseguridad.

Por último, en este análisis, que se podría denominar de geografía política de la ciudad, se ha buscado aportar algo en lo que la geografía política no es buena: estudiar la construcción de paz. De hecho, como se deduce de los trabajos de varios autores (Gregory, 2010; Koopman, 2010, 2011; Megoran, 2011), la geografía política, en las diversas escalas de análisis, es muy buena estudiando la guerra y deficiente abordando la paz, porque, cuando se trata de la primera, esta es elocuente, teórica, interdisciplinaria, comprometida y construye una crítica convincente y estimulante de las culturas y las prácticas de la guerra. Mientras, para tratar la paz, la construcción de alternativas a la inseguridad y alternativas de seguridad, hay pocos conceptos y poco contenido. El hecho de que, como dice Koopman en su Alter-geopolitica, otras seguridades están tomando lugar (other securities are happening) es un llamado a prestar más atención a la relación entre acción colectiva contestataria y popular y la securitización del espacio.

\section{Referencias}

Alape, A. (1995). Ciudad Bolivar: la hoguera de las ilusiones. Planeta.

Asociación Siglo XXI, Jorge. (2011). Comunicación personal.

Baer, J. A. (1998). Cities of hope: people, protests, and progress in urbanizing Latin America, 1870-1930. Westview Press.

Benavides, O. (2011). Comunicación personal.

Consortium, C. P. (1994). Understanding community policing: a framework for action. The Bureau.

Departamento Administrativo de Bienestar social, Alcaldía Mayor de Bogotá D.C., "Para seguirle la línea a la vida", documental sobre la movilización de 2004 en Bogotá. 2008. Recuperado de http:// www.youtube.com/watch?v=JOkdKX RYiYE\&feature $=$ youtube_gdata_player

Dussel, E. (2006). 20 tesis de politica. Siglo XXI.

Escobar, A., \& Restrepo, E. (2010). Territorios de diferencia: lugar, movimientos, vida, redes. Envión Editores.

Friedmann, R. (1992). Community policing: comparative perspectives and prospects. Recuperado de https://www.ncjrs. gov/App/abstractdb/AbstractDBDetails.aspx?id=157611

Goldstein, H. (1987). Toward communityoriented policing: potential, basic requirements, and threshold questions. Crime \& Delinquency, 33(1), 6-30.

Greene, J. R., \& Mastrofski, S. D. (1988). Community policing: rhetoric or reality. New York: Praeger. Recupera- territarias 31 


\section{territarias 31}

do de http://www.ncjrs.gov/App/ abstractdb/AbstractDBDetails. aspx?id= 115735

Gregory, D. (2010). War and peace. Transactions of the Institute of British Geographers, 35(2), 154-186.

Harvey, D. (2000). Spaces of hope. Berkeley, CA: University of California Press.

Harvey, D. (2004). El nuevo imperialismo. Ediciones AKAL.

Harvey, D. (2007). Espacios del capital. Hacia una geografía crítica. Madrid: Ediciones AKAL.

Herrera, M. C., \& Chaustre, A. (2012). Urban violence, memory and right to the city: youngsters' experiences in Ciudad Bolívar. Pro-Posições, 23(1), 65-84.

Jacobs, J. (1961). The life and death of great American cities. New York.

Koopman, S. (2010). Making space for peace: international accompaniment as alter-geopolitics. Antipode, 42(1), 231-235.

Koopman, S. (2011). Alter-geopolitics: other securities are happening. Geoforum, 42(3), 274-284.

Red Juvenil e Infantil de Promotores de DD. HH. (2005). Folleto de la Red Juvenil e Infantil de Promotores de DD. HH. Bogotá.

Mançano, B. (2009). Sobre a tipologia de territórios. En Territórios e territorialidades: teorias, processos e conflitos (pp. 197215). São Paulo: Expressão Popular.

Mançano, B. (2012). Movimentos socioterritoriais e movimentos socioespaciais: contribuição teórica para uma leitura geográfica dos movimentos sociais. Revista Nera, (6), 24-34.

Mantilla, P. (2007). Historia del movimiento juvenil en Ciudad Bolívar. En Historia del movimiento juvenil. Recuperado de http://historiajuvenilciudadbolivar. blogspot.de/

McAdam, D., McCarthy, J. D., \& Zald, M. N. (1988). Social movements. Recuperado de http://psycnet.apa.org/psycinfo/1988-98432-021

McAdam, D., McCarthy, J. D., \& Zald, M. N. (1996). Comparative perspectives on social movements: political opportunities, mobilizing structures, and cultural framings. Cambridge University Press. Recuperado de http://books.google.es/ books?hl=es\&lr=lang_de|lang_es $\mid$ lang_ fr|lang_en\&id=8UamWMisjtkC\&oi=fnd\&pg=PR7\&dq=John+McCarthy+ Mayer + Zald\&ots=DuNw04itDf\&sig= q-OPcq9anOIO-3dlBxe_Bl_vkAE

McAdam, D., Tarrow, S., \& Tilly, C. (2003). Dynamics of contention. Social Movement Studies, 2(1), 99-102.

McCarthy, J. D., \& Zald, M. N. (1977). Resource mobilization and social movements: a partial theory. American Journal of Sociology, 1212-1241.

Megoran, N. (2011). War andpeace. An agenda for peace research and practice in geography. Political Geography, 30(4), 178-189.

Melucci, A. (1988). Las teorías de los movimientos sociales. En Cuadernos de Ciencias Sociales. Teoría de los Movimientos Sociales. Costa Rica: Flacso. 
Melucci, A. (1994). ¿Qué hay de nuevo en los nuevos movimientos sociales? En Los nuevos movimientos sociales: de la ideología a la identidad (pp. 119-150). Recuperado de http://dialnet.unirioja. es/servlet/articulo? codigo $=576393$

Melucci, A. (1999). Acción colectiva, vida cotidiana y democracia. México: El Colegio de México, Centro de Estudios Sociológicos México. Recuperado de http://en.scientificcommons. org/6902338

Moore, M. H. (1992). Problem-solving and community policing. Crime \& Just., $15,99$.

Nieto, E. (2014). Comunicación personal.

Oslender, U. (2007). Espacio, lugar y movimientos sociales: hacia una "espacialidad de resistencia”. Scripta Nova. Revista Electrónica de Geografía y Ciencias Sociales, 6, 105-132. Recuperado de http://revistes.ub.edu/index.php/ ScriptaNova/article/view/448

Peak, K. J., \& Glensor, R. W. (1999). Community policing and problem solving: strategies and practices. NJ: Prentice Hall Upper Saddle River. Recuperado de http://mysite.verizon.net/res12j$\mathrm{spm} /$ sitebuildercontent/sitebuilderfiles/peak_pp6_edited.pdf

Peña, L. B. (2008). Reflexiones sobre las concepciones de conflicto en la geografía humana. Cuadernos de Geografía, 17, 89-115.

Peña, L. B. (2011). Algunos elementos metodológicos para pensar espacialmente en ciencias sociales. Bogotá: CIDS, Universidad Externado de Colombia.
Peña, M. (2008). Una mirada hacia la vida. El Espectador. Recuperado de http:// www.elespectador.com/impreso/bogota/articuloimpreso-una-mirada-vida Red de Hermandad y Solidaridad con Colombia. (2005). Para que la vida siga siendo joven. Redcolombia.org. Recuperado de http://www.redcolombia. org/index.php/regiones/centro/ cundinamarca/2284-para-que-la-vidasiga-siendo-joven.html

Suárez, J. D. (2012). Comunicación personal. Miembro del colectivo Arto Arte.

Tabares, E. (2014). Comunicación personal. Tarrow, S. G. (2011). Power in movement: social movements and contentious politics ( $3^{\mathrm{a}}$ ed.). New York: Cambridge University Press.

Tilly, C. (2003). Contention over space and place. Mobilization: An International Quarterly, 8(2), 221-225.

Tilly, C. (2005). Social movements, 17682004. Boulder: Paradigm Publishers. Recuperado de http://www.citeulike. org/group/2546/article/781106

Tilly, C., McAdam, D., \& Tarrow, S. (2001). Dynamics of contention. New York: Cambridge University Press.

Tilly, C., \& Tarrow, S. (2006). Contentious politics. Oxford University Press. Recuperado de http://books.google.es/ books?hl=es\&lr=lang_de|lang_es|lang_ fr|lang_en\&id=DjWDqIjRx00C\&roi=fn $\mathrm{d} \& p g=P P 2 \& d q=$ sidney + tarrow $+\&$ ots $=$ 8xdRgnVF5d\&sig=KfbW9d7Ka_UoMEKaGXfpf2DVt3I

Zibechi, R. (2008). Donde termina el asfalto: Cerros del Sur de Bogotá. territarias 31

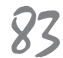

